\title{
HEGEL JUVENIL: ENTRE BERNA Y FRANKFURT*
}

Cuando nace Hegel se está agotando la Ilustración alemana y se inician el Sturm und Drang y el romanticismo. ${ }^{1}$ En el joven filósofo pueden percibirse ambas influencias. De la Ilustración conservará el espíritu crítico; del romanticismo, tanto su aspiración de absoluto como su deseo de un "ordo amoris" muy peculiar; de una y de otro, el "entusiasmo". Es sabido que Hegel se opuso al romanticismo porque pensaba que los románticos actuaban con precipitación en un deseo por alcanzar, sin rigor ni disciplina el reino de lo "puro deseado". El mismo Fichte, que lo influyó decisivamente en su juventud, padecía, al ver del Hegel maduro, de esta misma precipitación de los románticos; en las Lecciones de historia de la filosofia dirá que Fichte fue un alma "poética y profética y siempre nostálgica". No importa ahora la justicia o la injusticia de esta aseveración. Lo cierto es que la obra hegeliana es en buena medida romántica por lo menos en dos sentidos de la palabra "romanticismo": emotividad y tendencia a una mistica que tiene sus orígenes en Böhme; sentido dinámico de la vida y la historia. En efecto: en el principio era la acción.

En la obra juvenil de Hegel aparecen influencias muy variadas: la de Kant, a quien llegó a equiparar alguna vez con Cristo (Hölderlin, por su parte, afirmó que Kant era el Moisés alemán); la de Fichte y la de Schelling, cinco años más joven que Hegel pero acaso en aquel momento más brillante

- Hegel, Escritos de juzentud, Fondo de Cultura Económica, México, 1978. La traducción es de Zoltan Szankay y José María Ripalda. El libro incluye los textos escritos entre 1794 y 1800. Deja a un lado textos de la primerisima juventud (por ejemplo $F e$ y saber); incluye, en cambio, obras y esbozos que son inéditos incluso en Alemania. Quiero recordar algunos hechos: la traducción fue iniciada por Zoltan Szankay. Al fallecer éste la prosiguió José María Ripalda, quien escribió su tesis doctoral sobre Hegel (Universidad de Madrid) y ha trabajado en los Archivos Hegel. Ripalda escribió además la introducción, las notas y recopiló la bibliografia definitiva. Ripalda explica por qué no incluye los textos primerisimos de Hegel: para hacerlo sería necesario establecer claramente su cronologia y "este trabajo está aún por hacer". Algunos de estos textos pueden, con todo, consultarse en el Apéndice al libro de H. S. Harris, Hegel's Development. Toward the Sunlight 1770-1801, Claredon, Press, Oxford, 1972. Por lo demás aparecerán en español en un futuro que esperamos no muy distante. Salvo algunas excepciones, este Hegel juvenil que ahora se nos presenta incluye los escritos de Berna y Frankfurt; no los de Tubinga.

Este artículo es un capítulo de una obra en prensa.

1 Kostas Papaioannou aclara este punto en Hegel, Filósofos de Todos los Tiempos, EDAF, Madrid, 1975 (la edición francesa es de 1962). A mi modo de ver el mejor libro sobre el joven Hegel es el ya.citado de Harris; sigue siendo interesante el libro de Lukács. José María Ripalda traza una biografía espiritual y social - socio-histórico-espiritual - tan excelente como apasionada. El libro es también del Fondo de Cultura Económica. Recuerdo que el primero que se ocupó de los primeros escritos de Hegel fue Dilthey, para quien era fundamental entender el sentido vital del filósofo. A pesar de las críticas a que lo somete Ripalda, el libro de Dilthey sigue siendo válido y profundo. 
que éste, ${ }^{2}$ la del mismo Hölderlin y esto no sólo en el poema Eleusis que Hegel le dedicó. Por otra parte, la admiración hacia la Revolución Francesa, hacia el pensamiento de Rousseau y Montesquieu le llevaron a una actitud política radical que los años habrian de modificar. ${ }^{3}$

Hasta aquí estas breves coordenadas incompletas pero tal vez suficientes para entender las primeras obras de Hegel, a veces abstractas, a veces apasionadas, siempre vivísimas. Ciertamente, dentro de un mismo texto - sea el caso de un texto sobre la religión - aparecen problemas de orden social, político, incluso económico. De ahí la dificultad que presenta un análisis temático de los Escritos de juventud; me limitaré a las siguientes calas:

1. Análisis de los escritos sobre Religión;

2. Los esbozos de sistema;

3. Fragmento de poema.

Antes de pasar a estos puntos debemos preguntarnos: ¿son los escritos del joven Hegel esto que llamamos filosofía? Todo depende de lo que entendamos por esta palabra. Conviene recordar que José Gaos, para distinguir el pensamiento en lengua española del pensamiento sistemático que se desarrolla en otras regiones y tiempos, dice que el pensamiento del mundo hispánico es precisamente pensamiento. La idea de Gaos es parcialmente exacta; es también insuficiente. Si aceptáramos que no son filosofos quienes se expresan fuera de un sistema deberíamos proclamar ajenos a la filosofía, no sólo a los que piensan en nuestra lengua, sino, entre otros, a Pascal, Kierkegaard, Nietzsche. Por otra parte - aunque sean minoría - existen en nuestros filósofos verdaderos creadores de sistemas: dejo aparte a los teólogos; no quiero olvidar los verdaderos sistemas de Ramón Lull o Francisco Suárez. Tal vez lo que cabría decir es que hay modalidades distintas de hacer filosofía; habria que decir también que la filosofía auténtica es la que alcanza no tanto un saber esquematizado, sino una forma de la sabiduría. En cuanto al joven $\mathrm{Hegel}$, tiende a veces al ensayo, a veces al sistema, a veces al esbozo para un sistema futuro. Habría que añadir, además, que algunos temas hegelianos escritos entre los 21 y los 30 años, no atañen directamente a la filosofía. De ahí que mi referencia a ellos sea muy breve. Pasemos a los escritos de Berna y de Frankfurt. Veamos lo que Hegel tiene que decirnos en primer lugar sobre la religión. ${ }^{4}$

\section{Escritos sobre la religión}

Los escritos juveniles sobre temas religiosos son tan interesantes como discutibles. Parece necesario recordar, en este punto, que la religión representará un papel de primera importancia en los escritos del Hegel maduro. ${ }^{5}$ Es de

2 Este brillo aparece en las cartas de Schelling publicadas en estos Escritos de juventud.

3 No es vano recordar la gran amistad que ligó a Hegel con Hölderlin y Schelling.

4 El ideal de alcanzar un sistema definitivo es típico del idealismo alemán. Este ideal se expresa en estas palabras de Schelling: "Sentaré los primeros principios de toda filosofia, en los cuales se unen la razón teórica y práctica". (Carta escrita en la Noche de Reyes de 1975, incluida en los Escritos de juventud.)

s Las obras más sistemáticas de Hegel, son la Fenomenologia del espiritu (1807), La ciencia de la lógica (1812) y sobre todo la Enciclopedia de las ciencias filosóficas (1817). 
todos sabido que cuando Hegel nos habla del Espíritu Absoluto - la más alta expresión de la conciencia - sitúa al Arte en el primer grado de esta sabiduría detinitiva; las dos formas supremas del saber son justamente la religión y, verdad de todas las verdades, "círculo de los círculos", la filosofía. No será ésta exactamente la actitud de Hegel ante la religión en sus años mozos. En efecto, Hegel oscila entre la crítica (y el drama de la conciencia religiosa) por una parte, y la aceptación de la religión como manifestación suprema de la conciencia por otra.

Los escritos de juventud que más claramente remiten a la religión son: La positividad de la religión cristiana (1796-97) - época de Berna-; Esbozos para "El espiritu del judaismo" (1796-1798), Esbozo sobre religión y amor (1797-1798), Esbozos para "El espiritu del cristianismo" (1798-1799), El espiritu del cristianismo y su destino (1799).

No todos estos escritos tienen la misma intención: los Esbozos sobre religión y amor ponen de manifiesto la actitud religiosa del propio Hegel; los demás intentan un análisis objetivo - a veces muy ligado a los hechos, a veces harto abstracto - del desarrollo de las religiones y, especialmente, de un tema que preocupa a todos sus contemporáneos: el de la "positividad" de la religión y el de las relaciones entre religión, Iglesia y Estado.

La positividad de la religión cristiana es sobradamente rígido; es también de interés especial para ver uno de los aspectos de la actitud del Hegel juvenil: justamente el de la positividad.6

Las ideas de Hegel acerca de la religión se originan parcialmente en Kant, parcialmente en las formulaciones más "eticistas" de la tradición protestante de la cual el filósofo cree haberse alejado sin que este alejamiento sea nunca del todo real. El tema del escrito es, a grandes rasgos, sencillo: se trata de mostrar que una religión se convierte necesariamente en religión positiva y acaba por formar una "secta" que, en el curso de la historia, se aliará al estado. Esta idea tiene, sin duda, elementos de verdad; deja de ser verdadera cuando afirma que ningún cristiano lo ha sido verdaderamente, salvo Jesús. ${ }^{7}$

Escribe Hegel: "la finalidad y esencia de toda religión verdadera", la nuestra incluida, "es la moralidad de los hombres". Cierto, Hegel cambiará radicalmente de punto de vista en cuanto a Jesús a partir de los textos de Frankturt, pero nunca dejará de ver la religión como una suerte de universo ético o, por lo menos, como un universo espiritual vinculado a la ética.

Esta idea $-\mathrm{y}$ vivencia - de la religión está vinculada tanto a la época en que Hegel vivía - y al pensamiento filosófico alemán de esta época- como

En ésta se nos ofrece, de manera compacta y a veces difícil, la totalidad de este sistema totalizador. Es en la Enciclopedia donde es más clara la definición de la filosofia como "círculo de los ćrculos" porque en ella Hegel muestra cómo, a partir del Ser, noción abstracta y en cierta medida "vacia", la conciencia se va llenando de contenidos cada vez más "concretos" hasta alcanzar - cierre del círculo-- la Idea absoluta objeto de la filosofía.

6 Harris observa, con certeza, que el paisaje suizo que Hegel describe nunca llegó a emocionarle. Harris atribuye esta actitud a la situación de Hegel en Berna. Podrla atribuirse también a un talante rígido del cual Hegel podrá liberarse en Frankfurt.

7 ¿No serían espiritus cristianos, en un alto grado de pureza, Eckhart, Ruysbroek, San Juan de la Cruz? El Hegel de Berna no los tiene en cuenta. 
a sus propias tradiciones culturales. Pero, a no dudarlo, una religión que fuera solamente o esencialmente ética sería un hueco de religión, una religión precisamente limitada por la "eticidad".

Regreso a La positividad de la religión cristiana. Jesús aparece aquí como aquel que vino a iluminar a los judíos para devolverles su espíritu original. Pero Jesús tracasa ${ }^{8}$ y este su fracaso se encuentra ya en sus discípulos y, de manera más marcada, en la historia posterior de las iglesias cristianas que se convertirán en "sectas" de una "secta" primera. La palabra "secta" no deja de ser reveladora porque ver la religión como una secta es negar el carácter esencial (personal y personalizador) de la religión. ¿Es posible sostener que los Padres de la Iglesia actuaban por "motivos muy mezclados" y mediante "cálculos muy poco santos"? No creo que lo sea pero dejemos este punto. Si el cristianismo es una "secta" no es ya para Hegel una secta verdaderamente religiosa; es mucho menos todavía una "secta filosófica". En la persona de Jesús se revelan, al mismo tiempo, el conocimiento del deber y la obediencia a la voluntad divina convertidas en fe y en mandamientos que están en el origen de los actos virtuosos. El propio Hegel tendrá que cambiar más tarde de postura: sabrá separar los actos virtuosos y la ética de algo superior: la fe $y$, ante todo, el amor.

Según el escrito de Berna, este Jesús ético realiza milagros. A diferencia de Hume, a quien ya Hegel pudo haber conocido en estos años, cree que los milagros son necesarios: otorgan a Jesús una autoridad -Jesús aquí más autoritario que amoroso- ante sus discípulos. Al morir Jesús, sus discípulos -embrión de la secta cristiana - se inclinan ya a la "positividad". La libertad que Jesús mostraba no se recibe ya entre sus discípulos inmediatos porque éstos estaban tan ligados a Jesús que sus ideas y sentimientos dependían exclusivamente de $\mathbf{E}$. Ya solos, entrarán en los dominios de lo "positivo".

La autoridad exige obediencia y la relación autoridad-obediencia no es tan clara como pensaba Hegel que lo era. Lo que es sin duda cierto es que el cristianismo quiso difundirse por el mundo. "Esta manera de difundir una religión sólo puede corresponder a una fe positiva." La primera comunidad cristiana que suprime la propiedad y proclama la comunidad de todos los bienes renunciará poco a poco a sus ideales. Ciertamente Hegel critica con bastante dureza la propiedad privada aunque no la rechace nunca del todo y la acepte definitivamente en su madurez. La propiedad forma parte de la positividad. Más claramente positivo se vuelve el cristianismo al correr de los siglos hasta llegar a unificar la religión y el Estado.

Paso a este punto. Observemos, sin embargo, antes de precisarlo algo más, que las preocupaciones sociales de Hegel eran varias: por una parte deseaba

8 Kostas Papaiannoau ha mostrado con gran claridad la relación entre este fracaso y el fracaso del espíritu cristiano en Dostoyevsky. ¿Habria que ver en esta idea del fracaso una vivencia trágica en el propio Hegel? Es por lo menos tentador pensarlo.

9 Es evidente que la autoridad de Jesús no provenía únicamente de sus milagros. Habria que preguntarse hasta qué punto Hegel creyó en la divinidad de Jesús. En el escrito de Berna su posición no es clara aunque a veces parece pensar que lo que tiene Jesús de divino es aquello que, en potencia, tienen de divino todos los hombres. Con todo, Jesús sigue siendo, aun en este caso, superior a los demás hombres. 
la unidad de Alemania y en esto coincidía con Maquiavelo cuya obra Hegel volvió a reivindicar; por otra parte Hegel asumía una actitud totalmente crítica ante la unión Iglesia-Estado en su época y especialmente en su tierra.

Pero, ¿qué sucede cuando la religión se convierte en comunidad para, más tarde, convertirse en Estado? Escribe Hegel: "La supervisión de la moralidad cristiana es el objeto principal de ese Estado eclesiástico" pero el EstadoIglesia quiere legislar sobre lo ilegislable: los "vicios", las "inclinaciones desviadas", que "no pueden ser objetivo de un Estado eclesiástico". Además, la Iglesia "se ha vinculado siempre al Estado". Tal vinculación es conflictiva (el Estado no puede legislar en materia de religión; la Iglesia no debe "legislar" en materias sociales o políticas). Ha sucedido, sin embargo, que la Iglesia absorbió al Estado cuando "un Estado en cuanto Estado civil, no debería adherirse a fe alguna". En la Iglesia se ha perdido la "libertad de opinión que existio en los orígenes; el Estado ha perdido su autonomía. La Iglesia de la Alemania del siglo xviI ha regresado a una actitud típicamente judía: "Así, los cristianos han vuelto allá donde estuvieron los judíos." La característica de la religión judía es la de "la servidumbre bajo una ley".

Muchas de las interpretaciones de Hegel son discutibles. Es probable con todo, que la razón le asista cuando denuncia la fusión Iglesia-Estado en la Europa que nace a partir de la formación de las nacionalidades. El radicalismo de Hegel -que no ignora la tolerancia - tiene sus raíces en el "entusiasmo" critico de la Ilustración.

Tales son las tesis esenciales en la positividad de la religión cristiana. Aun cuando en obras posteriores mantendrá algunas de las ideas de la época de Berna, habrá de alterarlas y modificarlas en la época de Frankfurt.

En los Esbozos para el "Espiritu del judaismo", Hegel es doblemente injusto: lo es hacia el espíritu mismo del judaísmo y lo es en relación a la historia. Su tendencia a ver el judaísmo como un todo semiestático, elige dos símbolos principales: el de Moisés y el de Abraham.

Moisés, el hombre que urdió el plan de liberación de su pueblo, alcanzó la "unidad" del "ser" de los judios. A Moisés se debe que la religión judia sea fundamentalmente legalista. Para esta religión "el individuo particular estaba totalmente excluido" del interés activo por el Estado. Moisés fracasó porque el pueblo que quiso elevar al nivel de un "pueblo de iguales" no estaba preparado. La igualdad política era así de signo contrario a la igualdad "republicana". La igualdad a la cual aspiraba Moisés era la de la "insig. nificancia". Sorprendente esta idea de confrontar un tipo de república moderna con otros modos de sentir y de ver; sorprendente también la imagen que Hegel se hace de su símbolo: Moisés. Pero no termina aquí la crítica. Moisés, hombre "fanático", es seguido por grupos de judios, los cuales también fracasan al querer convertir la vida interior en ley.

Hegel había lefdo el Antiguo Testamento. Veremos, más adelante, cómo Hegel habrá de decirnos que Jesús vino realmente a superar la "legalidad" judía. Pero el caso es que dentro del mismo Antiguo Testamento ni Moisés es un fanático ni se pueden olvidar estos espíritus luminosos que son, entre otros, Job o Salomón. 
Peor que la interpretación de su Moisés, es la que Hegel hace de su Abraham, siempre extranjero en su tierra. Abraham actuó solamente en busca de un "instinto de seguridad". Esto lo condujo a verse como único y como Unidad para proyectar después esta Unidad fuera de sí, hacia un Dios unitario que constituia su "seguridad personal". Ante la Unidad, los judios sentían temor, el servidor de Dios, el judío, era así un "esclavo". ¿No es cierto que Abraham tuvo alguna vez amor hacia su hijo? Esto se explica -o así lo explica Hegel_ como forma del "escrúpulo" y este escrúpulo se hizo tan fuerte, que Abraham "estuvo dispuesto también a matar" a su hijo. La historia parece repetirse a partir de Noé. Pero no sigamos con más detalles. $\mathrm{La}$ pregunta es ahora esta: ¿qué es lo que hizo que Hegel hablara así del pueblo judío casi siempre en contraposición al pueblo griego, signo de libertad? No se trata de racismo - los puntos de vista de Hegel son ante todo culturales y morales; no biológicos. Lo que Hegel intentó -también lo intentó Schelling - fue fundar una nueva religión. ${ }^{10}$ Esta religión sería la del amor activo opuesto a la "pasividad" del pueblo judío que Hegel veía desde el espejo distorsionado de su Ilustración. Hegel quiso alcanzar el "pleroma". No lo encontraba en el judaísmo ni tan sólo en el cristianismo. Hubiera querido encontrarlo en aquella "revolución espiritual" que preconizaba Schelling. ${ }^{11}$

La idea de Hegel en cuanto a la religión ${ }^{12}$ no le dejaba ver el sentido profundo de las religiones ni de aquella que él mismo llamaba "nuestra" (el cristianismo). Moisés, Abraham, Isaac se le convierten en símbolos abstractos por cuyos huecos escapa la vida.

Ya he indicado cómo se presentaba, para Hegel, el cristianismo. No insistiré sobre sus argumentos acerca de la "positividad de la religión" y solamente los mencionaré cuando sean necesarios para entender mejor su pensamiento. La idea central es ahora ésta: Jesús - incomprendido por todostiene en sí algo que no tuvo Hijo del Hombre alguno: vocación ferviente de amor.

La pregunta radical es ahora la siguiente: ¿qué es el cristianismo? Veamos lo que el Hegel de Frankfurt dice para contestar a esta pregunta.

La segunda parte de El espiritu del cristianismo y su destino se inicia con Jesús. En la parte inicial se repetían, algo ampliados pero no alterados, los que he llamado "símbolos" del mundo judaico: Moisés, Abraham, algo más "históricamente" Flavio Josefo.

10 De este intento da abundantes ejemplos José María Ripalda en el libro ya citado: La nación dividida.

$11 \mathrm{El}$ intenso interés por formas de pensamiento hermético (el de Böhme, por ejemplo), es una característica clara del pensamiento religioso de Hegel. Su poema Eleusis es buen ejemplo de esta tendencia. Por otra parte, la influencia hermética de Bruno en Schelling es patente. Lo cual no significa que deba interpretarse todo lo que Hegel dice bajo el signo de las religiones ocultas; significa, tan sólo, la presencia en él y en sus amigos, de elementos de corrientes ocultas.

$12 \mathrm{El}$ gran cambio entre el Hegel juvenil y el Hegel maduro consistirá en situar la religión como fin supremo (época de juventud) y en subsumir la religión a la filosofía (época de madurez). 
Ante este pueblo apegado a sus tradiciones legalistas no pudo cumplirse la "esperanza de los romanos" que consistía en "aplacar" el fanatismo judio. Con Jesús comienza otra era histórica y espiritual. Jesús combate a los judíos y no combate solamente una parte del judaísmo sino que se "enfrenta a su totalidad". También ahora Jesús fracasa al no alcanzar una influencia decisiva en su pueblo aun cuando esta influencia sea decisiva en otros pueblos de la Tierra. Lo que Jesús opone al mundo judío -y a su "positividad"- es el amor. En rigor, Jesús no propone ya "mandamientos": a ellos opone "el impulso y la necesidad humana". Acto verdaderamente religioșo si por religión entendemos, con Hegel, lo "más espiritiual" y lo "más bello". Belleza: palabra nueva y significativa que no habia aparecido todavía en los escritos de juventud. Y es que Hegel llega a unificar (cosa que ya no hará en su madurez) religión y belleza. En otras palabras, ahora predomina la actitud "estética" sobre la actitud "ética". Jesús viene a cambiar el mundo, a acabar con la estaticidad y la objetividad (aqui en el sentido de algo pétreo e inmóvil). Jesús trae al mundo la "subjetividad" viva.

Ciertamente Hegel piensa que Jesús vino a traer una nueva "ley" pero esta ley está más allá de las leyes. Ciertamente existen en las palabras de Jesús "mandamientos", pero éstos no se manifiestan en formulaciones "opresoras" como las de Moisés porque ahora se trata de mandamientos dentro de lo "vivo pensado" y no de conceptos "abstractos". Jesús transpone los limites de la ética; su enseñanza es enseñanza de amor y en el amor desaparece "todo pensamiento de deber". Es claro que en este punto Hegel implícitamente critica a Kant. Y, ya más explfcitamente, piensa que en la filosofía de Kant se entremezclan dos errores: a) el de unir ley y deber; b) el de afirmar contradictoriamente que los deberes son "una realización hecha con agrado". Contradicción, efectivamente, porque "los deberes exigen una oposición, mientras que el hacer con agrado supone la ausencia de la misma".

En el curso de su escrito, Hegel coloca en íntimo contacto la vida, la belleza y el amor. El "concepto" queda "desalojado por la vida" y la experiencia particular (subjetiva) es más importante que los conceptos abstractos. "Jesús opone a un mal mandamiento el genio superior de la reconciliación (una modificación del amor) que no sólo actúa contra esta ley sino que la hace completamente superflua, pues abarca en si una plenitud tan viva y tan rica que para El, algo tan pobre como la ley ni siquiera existe." Hegel es injusto con los Padres de la Iglesia. Parece olvidar, o ignorar, que hubiera podido recurrir por lo menos a uno de ellos: San Agustín. Hegel piensa que el cristianismo se deforma en el curso de la historia. Pero no percibe que los cristianos pudieron llegar a la esencia del cristianismo después de que se fundara la Iglesia. San Agustín decía: "Deus meus, pondus meus" y dirigiéndose al hombre le decía: "Ama et fac quod vis" porque el que de veras ame necesariamente hará el bien. Tres pueden ser las razones de los olvidos frecuentes de Hegel: el espejo de la Ilustración con el cual mira la evolución de las religiones; la presencia, en Alemania, de una Iglesia que es el Estado; su propio deseo de fundar una nueva religión.

El amor, la belleza, superan a los deberes. Lo cual no significa que en la 
doctrina de Jesús no existieran importantes elementos de moral. En este sentido "Jesús opuso el hombre a la positividad de los judios; a las leyes opuso las virtudes y en estas se cancela la inmoralidad del hombre positivo". Los mandamientos morales auténticos "proceden de la vida". El destino -el de toda religión cuando se convierte en sistema social y el propio destino que nos creamos - limita las acciones de los hombres. Pero lo excepcional, en Jesús, es que pudiera "adormecer" el destino gracias al amor. Consideremos un caso extremo: el del criminal. "Ante la ley el criminal no es más que un criminal" pero el criminal no se define únicamente por su criminalidad: es un ser completo y el crimen no es sino un aspecto de su ser... puesto que el hombre es más que un pecado existente." Jesús supo ver la íntima relación entre el pecado y el perdón de los pecados (caso muy claro, el de María Magdalena); quiso reconciliar al hombre consigo mismo: " $\mathrm{La}$ vida ha reencontrado, en el amor, a la vida." Esta armonía hecha de belleza se muestra en la fe y la fe no es algo abstracto, es "conocer el espíritu por medio del espíritu". Nuevamente Hegel contrapone la enseñanza de Jesús a la que pensó ser la enseñanza de los judíos: "A diferencia del retorno judio a la obediencia, la reconciliación en el amor es una liberación: en vez del reconocimiento renovado de la dominación es la libertad suprema, la superación de la dominación en la unión viviente, de aquel espíritu de amor y de fe mutua concebido a partir de la dominación." La dominación existente puede, con todo, ser superada. Por tres medios, en el espíritu de Jesús (¿también en el "pleroma" de Hegel?): el anhelo de belleza, el amor, la vida verdadera.

Mencioné, más arriba, la palabra "virtud". La idea que Hegel se hace de la virtud es crucial para entender su obra juvenil. "El amor no sólo reconcilia al criminal con su destino; reconcilia también al hombre con la virtud." Lo cual aleja definitivamente a Hegel de las enseñanzas de Kant. Para éste la virtud es "sometimiento"; para Hegel es libertad.

Podría pensarse que existen virtudes absolutas (en el sentido de totales) pero la idea es doblemente contradictoria; por una parte, si todas las virtudes se redujeran a una sola virtud carecerfa de sentido hablar pluralmente de las virtudes; por otra parte, si cada virtud fuera absoluta entraría necesariamente en conflicto con otras virtudes. Lo que sucede es que hay que evitar concebir las virtudes como conceptos. Las virtudes se viven en el centro del amor. No se trata, sin embargo, de separar radicalmente las virtudes de las leyes. Se trata más bien de ver que la virtud -que puede existir objetivamente, es decir, socialmente — debe completarse por medio del amor para merecer verdaderamente el nombre de virtud. Y el amor es relación viva entre los hombres; no concepto ni pensamiento: "un ente pensado no puede ser algo amado." ${ }^{13}$

Si queremos entender más a fondo las ideas y vivencias de Hegel cuando

13 Estas ideas tienen poco que ver con las del Hegel maduro. Parecen más bien anunciar a un Kierkegaard, pensador de la existencia concreta y precisamente subjetiva. Naturalmente la gran diferencia entre Hegel y Kierkegaard es clara: para Hegel la religión tiene algo de estético; para Kierkegaard lo estético muestra el grado más elemental y negativo de la vida humana. Lo cierto, sin embargo, es que estas ideas que esboza el joven Hegel no reaparecerán ya en sus obras de madurez. 
piensa en Jesús, habrá que precisar el sentido mismo de la religión de Jesús, nuevamente contrapuesta por Hegel a la idea judaica de la religión.

Mediante el amor, Jesús supera "las barreras de la esfera de la moralidad": Jesús ve a Dios como Padre y como fuente vivificadora. El amor es vida, "vida pura" que es "ser". Para nombrar a esta vida carecemos de palabras; solamente podemos aproximarnos a ella por el "entusiasmo". Actitud a la vez romántica y tradicional; en el fondo, actitud "mística" que Hegel no acepta como tal. En los Apóstoles ve Hegel, nuevamente, un principio que llevará a la objetividad (es decir, lo inmóvil y más tarde, lo positivo). Hay aquí sin duda, una extraña paradoja. Si nos preguntamos cómo conoció Hegel a Jesús la respuesta es evidente: a través de sus discípulos. Si éstos empezaron ya a deformar la enseñanza de Jesús, ¿cómo pudo Hegel conocerla? No hay respuesta clara y es probable que no haya respuesta alguna a esta pregunta.

En cierto modo, las "ideas" de Jesús se anuncian en San Juan Evangelista quien interpreta el Verbo como ser. Sin embargo, "la idea de Dios, por más que se la sublime, conserva siempre el principio judfo de la oposición del pensamiento frente a la realidad, de lo racional frente a lo sensible". En cuanto a la relación entre el Hijo del Hombre y el Hijo de Dios, Hegel la considera misteriosa; es materia de fe. ${ }^{14}$ No hay oposición entre el Hombre y Dios, entre Jesús y su Padre: "fuera de la reflexión, esta separación y oposición, no tiene lugar". Dios, verdadero espíritu, está presente en todos los hombres. Quedamos en la duda: o bien Jesús es Dios y despierta en los hombres lo que tienen de divino o bien es un Hijo del Hombre privilegiado por su espiritualidad y por esto, aunque en grado sumo, hombre divino. En todo caso la relación Padre-Hijo solamente puede concebirse por medio de la fe: "la fe en lo divino proviene... de la divinidad de la naturaleza propia; solamente una modificación de la divinidad puede llegar a conocer la divinidad". ${ }^{15}$

Hegel analiza algunos sacramentos. Es interesante su interpretación del bautismo por inmersión, el que practicaba Juan Bautista: se trata de un símbolo de la infinitud bella y divina; por otra parte, todo lo que pertenece al "reino de Dios" - "armonía viviente de los hombres" - constituye otras formas del pensamiento religioso de Jesús. Pero este pensamiento o, mejor, este espiritu, empieza ya a borrarse en los discipulos. Ya en Marcos la insistencia en el "creyente" y el "bautizado" opuestos a los incrédulos y no bautizados empieza a manifestar —según Hegel_ cierta idea de "secta" y de grupo: se trata del primer paso hacia una religión positiva e institucionalizada. El pueblo

14 No olvidemos que en la Enciclopedia, Hegel compara su sistema a la Trinidad (Padre, Hijo, Espiritu Santo) aunque piense que la interpreta racionalmente... lo cual, sin duda, es extremadamente discutible. Tan sólo quiero recordar que, en la obra madura de Hegel, Dios (la Idea) pretende ser objeto de reflexión racional; nuevamente se diferencia el Hegel maduro del Hegel "entusiasta" de la juventud.

15 En todos los textos de juventud, la actitud de Hegel en cuanto a la divinidad real de Jesús es ambigua. Si Hegel creyera que Jesús es un espíritu privilegiado sus ideas estarian ya en el camino de quienes habrán de seguirlo y podrán decir, con Feuerbach, que cl único dios del hombre es el hombre mismo. Dos observaciones: que es claro que la visión que aquí tiene de Jesús es, en buena medida, romántica y "helenizada"; la idea de "modificación" podría ser de origen spinozista (las creaturas como "modos" de la Sustancia). 
judío no podía entender las enseñanzas de Jesús. La lucha de Jesús fue "pura y sublime" en buena parte porque "reconoció el destino en toda su dimensión porque se opuso a la totalidad del destino". Pero esta visión esencial no puede triunfar. "Jesús llevó todo a la tumba; su espíritu no quedó atrás con ellos" (es decir con aquellos discípulos que constituyen, paradójicamente, la única fuente de conocimiento que Hegel tiene del Maestro). En los discípulos ya no existe la misma conciencia de la belleza ni de la divinidad; todo empieza a "objetivarse" y a sectarizarse. La idea de lo divino prosigue a lo largo de los siglos pero la divinidad queda separada de la vida. Se escinden la religión y la fe viva y dan lugar - no hay que insistir ya sobre este punto- a una Iglesia-Estado, fusión de los que deberían ser contrarios: Estado e Iglesia. La necesidad de la separación entre la Iglesia y el Estado era vista como una necesidad por la Ilustración y por los idealistas alemanes. No lo era menos la necesidad de fundar una nueva religión basada en Jesús. La idea estaba seguramente muy arraigada en el grupo de amigos de Hegel. En una carta de 1794, Hölderlin escribe: "Estoy seguro que te has acordado a veces de mí, desde que nos separamos con la consigna 'Reino de Dios' " (La carta aparece en los Escritos de juventud).

Supongamos que fuera posible fundar una nueva religión; tno acabaría por representar objetivamente a la vida y convertirla en algo que no puede ser subjetivo?; es decir, eno se precipitaría la religión naciente en los dominios de la positividad?

La religión que Hegel proponía no es clara. Dispersos en sus escritos podemos encontrar algunos de sus aspectos esenciales.

"Religión, escribe Hegel, es veneración de la divinidad," Pero la religión no se limita a un puro venerar; hay en ella, tambiên, acción: "comprender es dominar". De lo que se trata, en verdad, es de modificar el mundo al "vivificar" los objetos, y convertirlos en "dioses". El filósofo debe participar en el Todo, darle un alma y convertirlo "en Dios" (intento que perdurará, con otros conceptos, en la obra madura). El mundo debe modificarse por medio de un amor que cura todas las escisiones y aúna todos los contrarios. De lo que se trata es de llegar a reconciliar la libertad y la naturaleza, lo real y lo posible. El amor que Hegel propone se expresa a veces de manera sorprendente: "Sólo puede producirse amor hacia aquello que es igual a nosotros, hacia el espejo, hacia el eco de nuestro ser." Frase, con todo, modificada, cuando leemos: "El amado no está opuesto con nosotros; es uno con nuestro ser."

$\mathrm{Y}$ aquí, dos observaciones: la idea de una nueva religión activa, capaz de cambiar el mundo y divinizarlo, se asemeja a la magia; por otra parte, ¿quién no verá -si suprime la palabra Dios- en estos textos la idea mediante la cual Marx define al comunismo en los Manuscritos de 44? 'No dice Marx que el comunismo es la solución del enigma de la historia y que lo es porque en él se unen el hombre y la naturaleza, el hombre y el hombre, la esencia y la existencia? Naturalmente, estos textos de Hegel no pudieron ser conocidos por Marx, quien conocía, claro está, expresiones de tipo semejante dentro del sistema hegeliano unificador, todo él, de los opuestos. 
Esbozos de "sistema"

Los dos textos que directamente se refieren a la posibilidad de un sistema del idealismo alemán, son de la época de Frankfurt: uno ha sido titulado Primer programa de un sistema del idealismo alemán (1796-1797); el segundo, Fragmento de sistema (1800).

La filosoffa es, en Hegel, como lo es la religión, vocación de entender el mundo; es igualmente deseo de cambiarlo. Para ello hay que fundar un sistema. Pero ¿por qué esta obsesión sistematizadora en los siglos xvir y xIx alemanes? La idea de sistema contiene varios ingredientes: dar una explicación racional de toda la realidad; dar esta explicación de manera definitiva o cuasidefinitiva; incluir en el cuerpo de la filosofía la totalidad de las disciplinas filosóficas y aun no filosóficas; alcanzar un pensamiento claro aun cuando sea difícil; ver la realidad y los hombres como "conjunto" (no es otro el sentido etimológico de la palabra sistema). Conocer, conocerlo todo.

En el Primer programa, del cual se conserva una buena parte, se encuentran ideas de Kant (a veces "superadas" por Hegel), ideas de Fichte, la nostalgia por Grecia y un igualitarismo social que tiene que ver con la Ilustración y la Revolución Francesa. La filosofía que aquf propone Hegel está todavia muy alejada de la que percibimos en sus obras "definitivas". Algo de lo que después será (racionalmente) el sistema de Hegel es, con todo, patente: el paso de la naturaleza al espiritu.

La filosofía se inicia en una ética. La idea general de esta ética parece proceder de Kant. Pero en el Primer programa es ya notable cierta autonomía en relación a Kant: la ética kantiana es solamente un "ejemplo" de una ética más completa. De hecho, lo que aquí Hegel llama ética es una "filosofía de las ideas" que si bien es parcialmente práctica no deja de ser fundamentalmente teórica. ${ }^{16}$ Aquí es donde parece definitiva la influencia tanto de Fichte como de Schelling. ${ }^{17}$ La idea fundamental es la de "mi mismo". En esta representación me veo no solamente como un ser libre sino como un ser totalmente libre.18 Esta idea es "creación de la nada". ¿El filósofo como creador del mundo? Quede la pregunta, por lo pronto, en pregunta. Lo que es cierto es que acaso precipitadamente - se trata de un esquema- Hegel dice: "descenderé a los campos de la física". Precisemos estos campos.

Es sabido que en la obra de madurez la naturaleza es la alineación que debemos superar. No parece ser exactamente lo mismo el descenso que Hegel propone en el primer Fragmento. En cuanto a la física, tiene en Hegel una doble intención: crear una "física en grande" y, para alcanzarla, no reducirse a la experimentación. Hegel estaría en lo cierto si pensara que la experimen-

16 En este sentido, y solamente en él, lo que aqui se llama ética parece anunciar la Ciencia de la logica.

17 Véase la segunda carta de Schelling contenida en los Escritos de juventud.

18 Este "mí mismo" es el que recuerda, cercanamente, al "Yo" de Fichte y acaso lejanamente sea en ambos un reflejo tanto del Yo trascendental de Kant -aunque aquí se trata de un yo existente y no sólo de un centro de la conciencia en general-, como del Cogito cartesiano. 
tación tiene que completarse con -y a veces fundarse en- las matemáticas. ${ }^{19}$ No es éste el sesgo de su pensamiento. Cuando se refiere a la física Hegel pretende "darle nuevas alas" y escribe: "Así si la filosofía da las ideas y la experiencia provee los datos podremos tener por fin aquella física en grande que espero de las épocas futuras." La física no tiene aqui que ver con las matemáticas sino con la moral y la "experiencia" debe ser "moldeada para un ser moral". No es fácil saber lo que entendía el joven Hegel por la palabra física. Lo que es claro es que en sus obras de juventud no se aísla el conocimiento de la moral.

Pero pasemos al meollo del asunto. Escribe Hegel: "de la naturaleza paso a la obra humana". En efecto, pasemos a lo que más tarde se llamará "filosofía del espíritu". Esta esfera, la más alta a la cual pueden aspirar los hombres, va más allá del "entendimiento" (Verstand), de la Razón (Vernunft), para alcanzar el espíritu (Geist).

En el Primer programa, todavía imbuido de fe revolucionaria, Hegel no piensa, como habrá de pensarlo más tarde, que el Estado sea "divino". ${ }^{20}$ Piensa, por el contrario, que el Estado es "mecánico". De ser así no puede existir una "idea" del Estado, de la misma manera que no puede existir la "idea" de una máquina. El proyecto de teoría de Hegel no es acaso, en este punto, del todo original. Es, sin embargo, importante para entender su desarrollo y ver cómo sus ideas variaron con los años. El Estado nos convierte en engranajes de una maquinaria que niega a la libertad: "Sólo lo que es objeto de libertad se llama idea." Por lo tanto, tenemos que superar el Estado. Muy cercano a los anarquistas Hegel propone, incluso, suprimirlo. Sin duda, habrá que escribir una filosofía de la historia pero ésta no servirá, como en años posteriores, para mostrar el progreso ascendente de la providencia en el curso de la historia de las naciones, sino para hacer ver "la miserable obra humana: Estado, gobierno, legislación". Hegel fue, sin duda, un revolucionario.

La crítica del Estado tiene su contrapartida en la salvación dentro de un mundo espiritual que es y será siempre para Hegel el mundo auténticamente real. En la misma línea en que deseaba buscar el espíritu de Jesús, Hegel anda en pos de "la libertad de los espíritus". Pero aquí libertad significa declaradamente que el hombre -Feuerbach, Stirner, Saint-Simon...- es su propio dios. En efecto, los hombres "no deben buscar ni a Dios ni a la inmortalidad fuera de si nismos".

Hombre-dios: ya había escrito Hegel que todo hombre tiene algo de divino; ahora, radicalmente, deifica al hombre y hace que lo relativo sea absoluto.

Mucho se ha escrito sobre la nostalgia que Hegel siente por Grecia. Esta nostalgia es típica del romanticismo alemán, del romanticismo inglés y encuentra sus raíces en el Renacimiento. Cuando Hegel se refiere a la libertad

10 Recuerdo, brevemente, los "momentos" por los cuales tendrá que pasar, de manera ascendente, el espíritu en el Hegel maduro: espíritu subjetivo, espíritu objetivo - cuya clave de bóveda será el Estado, "sustancia social consciente de sí misma" (Enciclopedia)- para finalmente llegar al Espiritu Absoluto (sucesivamente Arte, Religión, Filosofía).

20 Sería injusto pensar que Hegel fue, en su madurez, un estatista o un pensador "totalitario". Ciertamente, daba un alto grado de espiritualidad al Estado; sin embargo, éste debia estar al servicio del Espíritu Absoluto (véase nota anterior). 
absoluta piensa en Grecia y, específicamente, en Platón. La libertad proviene de la Belleza "tomando la palabra en el sentido platónico superior". El banquete y el Fedro, sin duda; pero la noción hegeliana de la Belleza no parece ser del todo la de Platón. La doctrina de Hegel afirma que un ser racional verá la razón suprema en un acto estético de tal modo que "la verdad y la bondad se ven hermanadas sólo en la belleza". Y añade: "La filosofía del espíritu es una filosoffa estética." Hegel no piensa como pensará Hegel después de 1807. Platón nunca sostuvo esta primacía única de lo estético ni de la Belleza. Por encima de lo Bello estaba lo bueno, el Bien Supremo. En cuanto a Hegel sabemos ya que no sostendrá que la Belleza sea el Espíritu Absoluto; éste, en su "momento" más álgido, será el terreno de la Filosofía cuyo objeto es la Idea. En suma, en los años de 1796-1797 estamos ante una actitud que Hegel llama racional pero que es, sin lugar a dudas, sobre todo emotiva, romántica y anarquizante. Poesía y filosofía se unen: "El filósofo tiene que poseer tanta fuerza estética como el poeta."

Recordemos que los sueños que tuvo Descartes en Ulm una noche del año de 1619, y que interpretó el propio Descartes durante su sueño, hacian de la poesła el grado más alto del saber humano. Para Hegel, en su vigilia, como para Descartes, en su vigilia soñada, Sabiduría $=$ Poesía.

Se sabe que los teólogos niegan la necesidad de la teología después de la muerte. Hegel prevé el final de la filosoffa y el final de la historia. El nuevo reino (¿el de la religión prevista por Hegel?) será el reino de lo poético: la poesía "será al fin lo que era al comienzo: la maesira de la humanidad". El punto es interesante por dos motivos: Vico habia señalado, por vez primera en la historia, la importancia de la poesía en el desarrollo de cada nación. Herder había aprendido algunas ideas semejantes de Vico (a quien Hegel no había leído en estos años). Además Vico había mostrado la necesidad de entender la mitología para entender la historia. También Hegel hace ver el interés de la mitología. Pero no en el mismo sentido. Lo que Hegel busca, paralelamente a una nueva religión, es una nueva mitología siempre que ésta se encuentre "al servicio de las ideas" y se convierta -ignoramos de qué manera - en una mitología de la razón.

La idea no deja de parecer (y acaso ser) peregrina; tiene sentido si vemos cómo concebła el joven Hegel la religión. De hecho, Hegel admite dos formas de la religión: una racional, la otra sensible. Esta es la que, con toda propiedad, constituye la mitología, necesaria para el pueblo pero también necesaria para los hombres ilustrados: si los ilustrados y el pueblo viven esta religión mitológica podrán llegar a entenderse: "Monoteísmo de la razón y del corazón, politeísmo de la imaginación."

La idea es en parte antigua: Maimónides habia pensado en dos tipos de expresión religiosa, una literal, la otra alegórica; Dante habia dicho que la Divina comedia podía leerse según la letra o según la alegoría; Averroes creía que se llegaba a Dios por dos caminos: el de la imaginación, el de la razón. La novedad que introduce Hegel no deja de ser más que curiosa: lo que la preside es la idea utópico-política de una humanidad en la cual todos los hombres sean iguales bajo el signo del espíritu. Debemos transformar las ideas 
en ideas estéticas (aquí identificadas con la mitología) y lograr que el ilustrado pueda pensar mitológicamente sin dejar de lograr que el pueblo piense racionalmente. Razón y mitología se unen para realizar, de manera harto sorpresiva y sorprendente, la igualdad que proclamaba Hegel con los hombres de la Ilustración. ¿La paz perpetua de Kant? Hegel la menciona explícitamente: se trata de alcanzar la paz mediante una razón mitologizada y un mito racional.

Progresista, el joven Hegel sitúa el paraiso perdido en el futuro: el "érase una vez" del tiempo mítico se convierte en "una vez será". ¿Qué es lo que será? La libertad absoluta. Hegel, en efecto, soñaba en una nueva religión, "la más grande obra de la humanidad".

El Fragmento de sistema de 1800 es un texto relativamente abstracto y en conjunto, menos interesante que el de $1796-1797 .^{21}$ Es posible que contribuya a su dificultad el hecho de que esté dos veces cortado. En conjunto es un escrito menos apasionado y menos interesante que el fragmento anterior. De ahí que aquí se trate con mayor brevedad.

Existen en el Fragmento de sistema claras muestras de la dialéctica hegeliana posterior. De hecho la primera frase (final de una frase) dice: “... existe una oposición absoluta". El fragmento repetirá las nociones de oposición y conflicto. La vida es múltiple; es, por una parte, pluralidad; es por otra parte individualidad (organización). Pero el ser relación entraña no solamente serlo en relación con los otros entes, sino también posibilidad de negación de sí misma ("pérdida de la individualidad").

Aclaremos algo más: la individualidad pensada (el concepto de individualidad) es unión consigo misma y lleva consigo igualmente pluralidad o multiplicidad. Sea el "hombre". Su ser es "uno", pero es "uno" dentro de la "infinitud de las vidas individuales". La vida, por una parte unitaria, es también fuente de multiplicidad en cuanto es infinita y se exterioriza en formas diversas de vida. Estas formas son infinitas y cada una de ellas es individual. Pero si partimos de una de estas manifestaciones ésta entraña la infinitud de la vida. A la unión de lo limitado e ilimitado llama Hegel "naturaleza".

Pero la naturaleza no es ya aquí naturaleza en bruto; es naturaleza pensada. La secuencia que propone Hegel parecería ser ésta: pensamiento, vida, naturaleza. El pensamiento que piensa a la vida se siente limitado. Al elevar la vida de la "infinitud finita" a la verdadera infinitud, el pensamiento se encuentra con otra vida "omniviviente y todopoderosa, y la llama Dios". No es otro el sentido de la religión: paso de la vida finita (o finitamente infinita) a la infinitud.

Dos ideas son aquí interesantes - a pesar de que el escrito, suficientemente oscuro, no las deje ver nunca como del todo diferenciadas. Primero: Hegel piensa nuevamente, como lo hizo en el fragmento primero y lo hará con mayor rigor en su filosoffa posterior, que la reflexión sobre el mundo tiene que conducir al espiritu. Segundo: que este espíritu (Dios) es la unión de los opuestos dentro de la "unidad vivificante". ¿Es este Dios la Idea que será obje-

21 Para distinguir este fragmento del anterior me referiré a él como Fragmento de sistema. 
to del análisis filosófico en la Fenomenologia, la Ciencia de la lógica, la Enciclopedia? La cosa no es clara. Hegel no deja de afirmar que la religión es materia de reflexión; pero esta reflexión es "subjetiva" y no puede decirse que se trate, todavía, de lo que más tarde Hegel llamará "filosofía".

Recordemos que Hegel parte del mundo para llegar a Dios; ${ }^{22}$ lo cierto es que, aun sin subsumir la fe a la reflexión, Hegel piensa que razón y fe son necesarias para entender a Dios. La reflexión por si misma no basta $y$, ahora cercano a su primer fragmento, Hegel piensa que un Dios "objetivo" solamente adquiere sentido por medio de la "alegria" (la de las ceremonias, ritos, ofrendas). Bruscamente termina aquil la primera parte del Fragmento de sistema. La segunda parte, breve y también secuencia de alguna parte ahora perdida, es oscura. En este subfragmento se afirma, por ejemplo, que la religión no siempre alcanza sus fines; para que logre alcanzarlos el pueblo del cual surge tiene que ser feliz. El texto de Hegel es relativamente enigmático. Lo que permanece claro es que, desde sus primeros intentos, Hegel trató de construir un sistema total, totalizador y probablemente definitivo.

Mucho perderá Hegel más tarde de su entusiasmo juvenil; mucho de su primer espíritu permanecerá en la obra posterior: el deseo insaciable por explicarse la totalidad del universo y explicárselo por el espíritu. Ast es especialmente significativo este fragmento de poema de 1789:

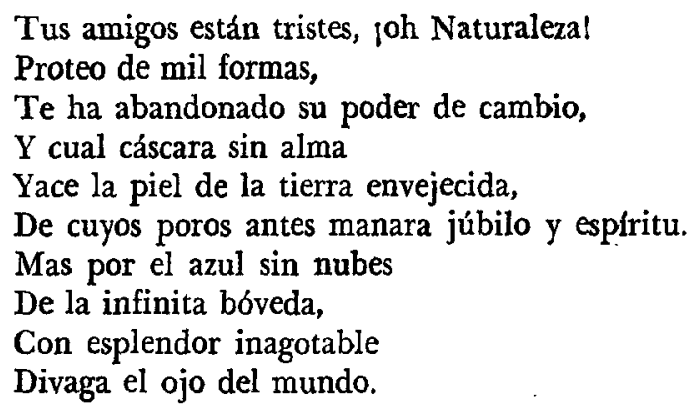

INSTITUTO DE INVESTIGAGiones Filosóficas

RAMón XIRAU Universidad Nacional Autónoma de Méxuco

22 Recuérdese que Hegel escribió sobre las pruebas de la existencia de Dios. Aquí parece aceptar la prueba a contingentia mundi aunque no lo diga explfcitamente. 